\title{
Charge-reversal Mass Spectra of Enolate Ions of Some Open-chain and Cyclic Ketones for Structure Identification
}

Thomas Sürig and Hans-Friedrich Griitzmacher $\dagger$

Fakultät Für Chemie der Universität Bielefeld, Postfach 8046, Universitätsstrasse, D-4800 Bielefeld 1, FRG

\begin{abstract}
The charge-reversal (CR) mass spectra of the enolate ions of heptanal and ten isomeric beptanones, of cyclobexanone, of cycloheptanone, of isomeric methylcyclohexanones, of isomeric ethylcyclohexanones and of the isomeric monoterpene ketones camphor, fenchone, pulegone and thujone were obtained by deprotonation using $\mathrm{OH}^{-}$ under chemical ionization conditions followed by collision of the $[\mathbf{M}-\mathbf{H}]{ }^{-}$ions with helium in the second field-free region of a VG ZAB 2F mass spectrometer. The CR mass spectra were evaluated by similarity index ( $S I$ ) values. Characteristic of the CR mass spectra of the open-chain enolates are fragment ions formed by $\alpha$-cleavage. However, the CR mass spectra are dominated by peaks of small hydrocarbon ions, particularly in the case of cyclic and bicyclic enolates. The CR mass spectra of enolates of linear heptanones differing in the position of the carbonyl group can be easily correlated with the structure of the parent ketone. The CR mass spectra of enolates of isomeric heptan-2-ones differing only in the degree of branching of the alkyl group are similar, but can be distinguished by the $S I$ values. The CR mass spectra of the enolates of the isomeric cyclic and bicyclic ketones studied are more or less identical and cannot be used for structural assignment.
\end{abstract}

\section{INTRODUCTION}

Negative chemical ionization (NCI) mass spectrometry ${ }^{1-3}$ has attracted considerable interest, in particular for analytical applications. It is a soft ionization technique especially suitable for the determination of the molecular masses of compounds with distinct electron affinities and of acidic substrates. In the NCI mass spectra of these compounds the base peak is usually due to $\mathrm{M}^{-\cdot}$ or $[\mathrm{M}-\mathrm{H}]^{-}$, and only a few fragmentations of these negative ions are observed. However, the peak pattern of the fragment ions in the mass spectra contains the structural information and is essential for a structure determination of the substrate. Spectra presenting structural information can be generated by collision-induced dissociation (CID) of organic ions in tandem mass spectrometry. ${ }^{4}$ However, the combination of NCI and CID mass spectrometry frequently affords inadequate results for a structural analysis because the main reaction of the negative ions induced by the collisions is an electron loss and only a few fragment ions are formed.

The collision-induced charge reversal (CR) of anions ${ }^{5}$ can be a useful method for assigning structures to nondecomposing negative ions. By this technique, two electrons of an even-electron anion are stripped by collisions with an inert neutral species in one-step (a)

$\dagger$ Author to whom correspondence should be addressed. and two-step (b) processes:

(a)

$$
\begin{aligned}
& \mathrm{m}_{1}^{-}+\mathrm{M} \rightarrow \mathrm{m}_{1}{ }^{+}+\mathrm{M}+2 \mathrm{e}^{-} \\
& \mathrm{m}_{1}^{-}+\mathrm{M} \rightarrow \mathrm{m}_{1}{ }^{+}+\mathrm{M}+\mathrm{e}^{-} \\
& \mathrm{m}_{1}{ }^{-}+\mathrm{M} \rightarrow \mathrm{m}_{1}{ }^{+}+\mathrm{M}+\mathrm{e}^{-}
\end{aligned}
$$

In particular mechanism (a) gives rise to vibrationally excited ions because the positive ions are created in a very short time by a vertical process and the geometry of the negative ion is preserved during this process. ${ }^{6}$ This excess energy can be used for excessive fragmentations, and in fact peaks due to surviving cations $[\mathrm{M}-\mathrm{H}]^{+}$are often absent in the CR mass spectra. ${ }^{?}$

Collision-induced fragmentations of enolate ions have been explored previously by Hunt and co-workers, ${ }^{8}$ Harrison and co-workers ${ }^{9,10}$ and Bowie and coworkers. ${ }^{11-17}$ It is an open question, however, whether the fragment ions observed in the CR mass spectra of large organic anions still carry the structural information of the original molecule. So far systematic studies of isomeric compounds indispensable for an evaluation of the CR method for analytical applications have not been performed.

As a test for analytical CR mass spectrometry, we report here on the CR mass spectra of enolate ions of some isomeric linear and cyclic ketones. The first group of compounds investigated were heptanal and ten isomeric heptanones with a different position of the carbonyl group and with a linear or branched carbon skeleton. This set of CR spectra reflect the effect of different types 
of structural isomerism in open-chain molecules on the fragmentation pattern. The second group included cyclohexanone, cycloheptanone and some isomeric alkyl cyclohexanones as examples of monocyclic compounds. Finally four monoterpene ketones were investigated as examples of natural products containing six-membered rings.

\section{RESULTS AND DISCUSSION}

In all cases the enolate ions were generated from the carbonyl compounds by deprotonation with $\mathrm{OH}^{-}$in a chemical ionization source, ${ }^{1}$ and the reaction of $\mathrm{OH}^{-}$ with all of the compounds studied produced $[\mathrm{M}-\mathrm{H}]^{-}$ ions exclusively. The charge reversal was achieved by collision of the $[\mathrm{M}-\mathrm{H}]^{-}$ions with helium in the collision cell of the second field-free region of a VG $\mathrm{ZAB}$ mass spectrometer. In most cases surviving $[\mathrm{M}-\mathrm{H}]^{+}$ ions were not detected, indicating a high excitation energy and a fast decomposition of the $[\mathbf{M}-\mathbf{H}]^{+}$ions resulting from the charge reversal. The exceptions are the $[\mathrm{M}-\mathrm{H}]^{+}$ions from the terpene ketone enolates. The CR mass spectra are analysed quantitatively by similarity indices $(S I){ }^{18}$ A value of $S I=65$ was obtained for identical enolate ions by multiple recording of the CR spectrum of the same enolate ion. Thus, $S I$ values of 65-180 characterize CR spectra which are not very different and which probably indicate mixture of different compositions of isomeric ions. However, SI values larger than 200 for two CR spectra clearly show that the spectra can be attributed to parent compounds of different structures.

\section{CR spectra of linear $\left[\mathrm{C}_{7} \mathrm{H}_{13} \mathrm{O}\right]^{-}$ions}

The enolate ions of heptan-4-one (1), heptan-3-one (2), heptan-2-one (3) and heptanal (4) were studied to reveal the effect of the position of the oxo group on the fragmentation of the charge-reversed $[\mathrm{M}-\mathrm{H}]^{-}$ions. The CR spectra are presented in Fig. 1 and the corresponding $S I$ values in Table 1 . It should be noted that the ketones 2 and 3 produce two isomeric $[\mathbf{M}-\mathbf{H}]^{-}$ions in a statistical ratio by reaction with $\mathrm{OH}^{-} .9,19$

The CR spectra of the $[\mathrm{M}-\mathrm{H}]^{-}$ions of 1-4 are clearly different. Specific information about the elemental composition and the origin of the fragment ions was inferred from the $C R$ spectra of labelled enolate ions derived from heptan-4-one-3,3,5,5- $d_{4} \quad\left(1-d_{4}\right)$ and $\left[{ }^{18} \mathrm{O}\right]$ heptan-4-one $\left(\mathbf{1 -}^{18} \mathrm{O}\right)$, respectively. The chargereversed enolate ions of 1 [Fig. 1(a)] produce ions of $m / z 71$ and 70 , and both ions are shifted completely by two mass units in the $C R$ spectrum of $1-^{18} \mathrm{O}$. Further,

Table 1. $S I$ values of the $C R$ mass spectra of the $[M-H]^{-}$ ions of 1-4

\begin{tabular}{ccccc} 
& 1 & 2 & 3 & 4 \\
1 & - & 1672 & 346 & 2047 \\
2 & & - & 1359 & 590 \\
3 & & & - & 864 \\
4 & & & & - \\
\hline
\end{tabular}

the $[\mathrm{M}-\mathrm{D}]^{-}$ions of $1-d_{4}$ generate ions of $m / z 73$ and 71 in their CR mass spectra. These results establish the elemental compositions $\left[\mathrm{C}_{3} \mathrm{H}_{7} \mathrm{CO}\right]^{+}$and $\left[\mathrm{C}_{3} \mathrm{H}_{6} \mathrm{CO}\right]^{+}$ for the ions of $m / z 71$ and 70 , respectively. The ion of $m / z 71$ is obviously the result of an $\alpha$-cleavage, but the ketene ion of $m / z 70$ may arise from a two-step chargereversal process. In this case the $\alpha$-acyl radical formed by neutralization of the enolate ion fragments to a ketene, which is reionized in the second step. The loss of $\mathrm{CO}$ from the ion of $m / z 71$ yields the abundant fragment ion of $m / z$ 43. Additional abundant peaks are observed for the fragment ions of $m / z 55,41,39$ and 27, in agreement with the results of Stringer et al. ${ }^{11}$ The ions of $m / z$ 55 correspond to the stable acroylium ions $\left[\mathrm{CH}_{2}=\mathrm{CHCO}\right]^{+}$, as shown by the expected mass shifts of 1 and $2 \mathrm{u}$ in the CR mass spectra of $1-d_{4}$ and ${ }^{1-18} \mathrm{O}$, respectively.

Analogously, the $[\mathrm{M}-\mathrm{H}]^{-}$ions derived from 2 fragment to the characteristic ions of $m / z 57\left(\left[\mathrm{C}_{2} \mathrm{H}_{5} \mathrm{CO}\right]^{+}\right)$ and $56\left(\left[\mathrm{C}_{3} \mathrm{H}_{4} \mathrm{O}\right]^{+}\right)$. The further fragmentations of these ions by loss of $\mathrm{CO}$ produce the ions of $m / z 29$ and 28 , the latter fragment ion appearing only in the CR spectrum of the enolate ions of 2. The most abundant ions of $m / z 43\left(\left[\mathrm{CH}_{3} \mathrm{CO}\right]^{+}\right)$and $42\left(\left[\mathrm{C}_{2} \mathrm{H}_{2} \mathrm{O}\right]^{+*}\right)$ in the $\mathrm{CR}$ spectrum of $[\mathrm{M}-\mathrm{H}]^{-}$ions derived from 3 are also due to the $\alpha$-cleavage product and to a ketene radical cation, respectively. Heptanal (4) is the only aldehyde studied. The main peaks in the CR spectrum of the enolate ion from 4 are due to ions of $m / z 27,29$ and 41 . The results show that the CR spectra can be conclusively linked to the structure of the precursor ketones. The most characteristic fragment ions are the acyl carbenium ions $[\mathrm{RCO}]^{+}$and the ketene radical cations $\left[\mathrm{R}^{\prime} \mathrm{CH}=\mathrm{C}=\mathrm{O}\right]^{+}$generated presumably by an $\alpha-$ cleavage in the $[\mathrm{M}-\mathrm{H}]^{+}$ions.

\section{CR spectra of branched $\left[\mathrm{C}_{7} \mathrm{H}_{13} \mathrm{O}\right]^{-}$ions}

The CR spectra of the enolate ions of the isomeric heptan-2-ones 3 and 5-11, differing only in the degree of<smiles>CC(=O)CCC(C)C</smiles>

5<smiles>CCC(C)CC(C)=O</smiles>

6<smiles>CCCC(C)C(C)=O</smiles>

7<smiles>CCC(CC)C(C)=O</smiles>

8<smiles>CC(=O)CC(C)(C)C</smiles>

9<smiles>CCC(C)(C)C(C)=O</smiles>

10 


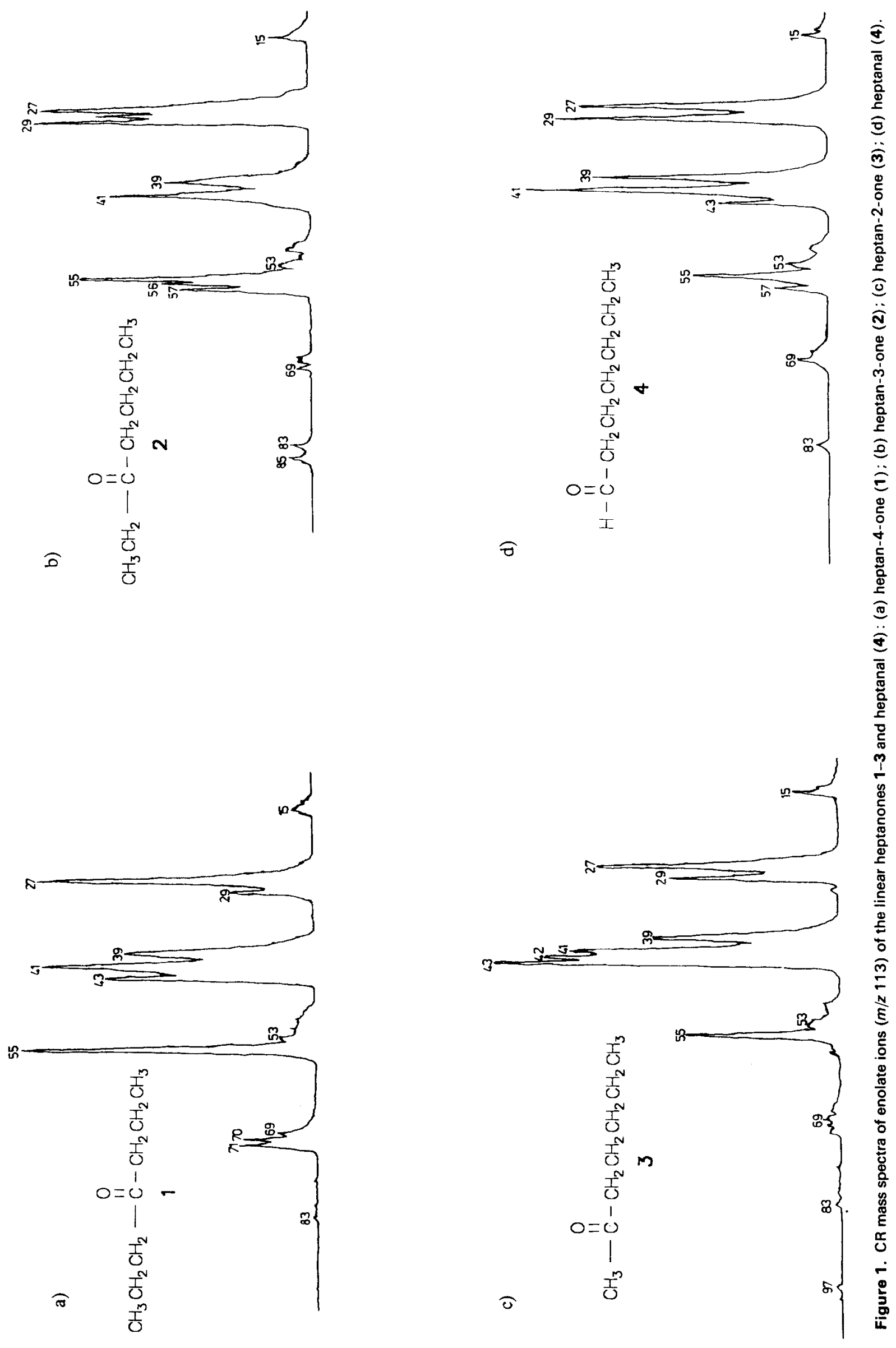


Table 2. CR mass spectra of enolate ions of the isomeric heptan-2-ones 3 and 5-11 $(\mathrm{m} / \mathrm{z}$ 113)

\begin{tabular}{rrrrrrrrr}
$m / 2$ & \multicolumn{1}{c}{3} & \multicolumn{1}{c}{5} & \multicolumn{1}{c}{6} & \multicolumn{1}{c}{7} & \multicolumn{1}{c}{8} & \multicolumn{1}{c}{9} & \multicolumn{1}{c}{10} & \multicolumn{1}{c}{11} \\
14 & 1.1 & 1.0 & 1.2 & 1.4 & 1.2 & 1.4 & 2.0 & 1.9 \\
15 & 2.1 & 2.2 & 2.0 & 2.1 & 1.7 & 2.2 & 1.8 & 2.4 \\
27 & 12.8 & 10.3 & 9.9 & 12.4 & 11.5 & 8.7 & 11.5 & 11.7 \\
29 & 8.9 & 6.1 & 9.7 & 7.6 & 8.7 & 8.4 & 8.1 & 6.3 \\
39 & 9.9 & 9.8 & 10.8 & 11.1 & 11.6 & 12.0 & 13.6 & 12.7 \\
41 & 14.0 & 14.0 & 14.9 & 15.7 & 15.2 & 15.4 & 17.3 & 16.2 \\
42 & 16.2 & 13.9 & 14.5 & 17.5 & 17.2 & 10.9 & 14.1 & 14.8 \\
43 & 19.3 & 24.0 & 17.9 & 16.4 & 15.1 & 15.7 & 10.3 & 16.5 \\
51 & 0.9 & & 1.5 & 1.5 & 1.5 & 1.7 & 2.2 & 2.3 \\
53 & 1.7 & 2.6 & 2.8 & 3.1 & 2.9 & 2.8 & 3.3 & 3.8 \\
55 & 8.6 & 8.9 & 5.9 & 6.3 & 8.5 & 6.6 & 7.4 & 6.8 \\
56 & 2.8 & & & & & 4.3 & & \\
57 & & & 2.2 & & 0.8 & 6.1 & 1.3 & \\
67 & 0.5 & + & 1.0 & 1.1 & 1.0 & 1.0 & 1.0 & 0.9 \\
69 & 1.0 & 0.7 & 3.7 & 2.1 & 1.1 & 0.6 & 0.8 & 1.1 \\
70 & 0.6 & + & & & & & 1.3 & \\
71 & 0.7 & 0.9 & 0.7 & 1.5 & 1.2 & 0.5 & 3.6 & 1.7 \\
81 & + & + & & & & & & \\
83 & + & + & 1.0 & & 0.6 & 2.7 & + & 1.1 \\
97 & + & + & + & & + & + & & \\
a Relative abundance $<0.5$. & & & & & \\
\hline
\end{tabular}

Table 3. $S I$ values of the $C R$ mass spectra of $[M-H]^{-}$ions of 3 and 5-11

\begin{tabular}{rrrrrrrrr} 
& 3 & 5 & 6 & 7 & 8 & \multicolumn{1}{c}{$\mathbf{9}$} & \multicolumn{1}{c}{10} & \multicolumn{1}{c}{11} \\
3 & - & 192 & 449 & 121 & 201 & 1245 & 288 & 170 \\
5 & & - & 382 & 354 & 337 & 585 & 273 & 522 \\
$\mathbf{6}$ & & & - & 560 & 80 & 200 & 259 & 514 \\
7 & & & & - & 212 & 1550 & 316 & 260 \\
$\mathbf{8}$ & & & & & - & 202 & 304 & 180 \\
9 & & & & & & - & 671 & 1422 \\
10 & & & & & & & - & 409 \\
11 & & & & & & & & - \\
\hline
\end{tabular}

branching of the pentyl group, are shown in Table 2. In agreement with the $C R$ spectra of $1-4$, the characteristic reaction is the formation of $\left[\mathrm{C}_{2} \mathrm{H}_{2} \mathrm{O}\right]^{+\cdot}(\mathrm{m} / z$ 42) and $\left[\mathrm{C}_{2} \mathrm{H}_{3} \mathrm{O}\right]^{+}(\mathrm{m} / z 43)$. The product ions of the cleavages at the other side of the carbonyl group, $m / z 99$ and 98 , are not observed. Instead, the other main fragments are the hydrocarbon ions of $m / z 27,29,39$ and 55 .

Because of the identical masses of the $\alpha$-cleavage product ions and ketene radical cations from the heptan-2-ones 3 and 5-11, the $S I$ values (Table 3) are definitely smaller than in the case of the positional isomers 1-4. Nevertheless, the $S I$ values of the isomeric heptan-2-one enolates are large enough for identification of the isomeric ketones by comparison with a set of reference spectra.

\section{CR spectra of the enolate ions from some isomeric cyclic ketones}

As an illustration of the CR spectra of the enolates of cyclic ketones, the $\mathrm{CR}$ spectra of the $[\mathrm{M}-\mathrm{H}]^{-}$ions of cyclohexanone (12), cycloheptanone (13), the isomeric methylcyclohexanones (14-16) and the isomeric ethylcyclohexanones (17-19) were analysed (Tables 4 and 5). Although fragmentation of the charge reversed cyclic enolates of 12 and 13 into smaller fragment ions<smiles>O=C1CCCCCC1</smiles><smiles>CC1CCC(=O)CC1</smiles><smiles>CCC1CCCCC1=O</smiles><smiles>CCC1CCCC(=O)C1</smiles>

17<smiles>CCC1CCC(=O)CC1</smiles>

Table 4. CR mass spectra of enolate ions of cyclohexanone (12) $(\mathrm{m} / \mathrm{z}$ 97) and cycloheptanone (13) and isomeric methyl cyclohexanones (14-16) $(\mathrm{m} / \mathrm{z} 111)$

\begin{tabular}{rrrrrr}
$m / z$ & \multicolumn{1}{c}{12} & \multicolumn{1}{c}{13} & 14 & \multicolumn{1}{c}{15} & \multicolumn{1}{c}{16} \\
13 & 0.9 & & & & 0.7 \\
14 & 1.4 & & 0.9 & 1.0 & 1.1 \\
15 & 1.2 & 1.6 & 1.4 & 1.4 & 1.0 \\
27 & 18.9 & 18.9 & 17.2 & 14.2 & 19.2 \\
29 & 2.9 & 6.3 & 4.5 & 3.4 & 4.9 \\
39 & 19.8 & 17.5 & 20.2 & 22.2 & 17.3 \\
41 & 18.4 & 22.7 & 16.3 & 17.0 & 13.8 \\
42 & 7.3 & & & & \\
50 & 3.2 & & & & \\
51 & & 2.8 & 3.6 & 3.8 & 4.1 \\
53 & 3.7 & 5.9 & 4.9 & 4.5 & 5.9 \\
55 & 12.3 & 19.9 & 13.2 & 13.1 & 18.1 \\
63 & 0.6 & & 0.7 & 0.9 & 0.6 \\
65 & 1.4 & 2.6 & 1.8 & 2.1 & 1.5 \\
67 & & 5.4 & 4.1 & 3.6 & 3.1 \\
68 & 4.8 & & 4.9 & 5.1 & 2.7 \\
69 & & & 2.1 & 3.8 & 1.4 \\
77 & 0.6 & 1.3 & 0.9 & 1.1 & 0.9 \\
79 & 1.2 & 2.0 & 1.8 & 1.6 & 1.5 \\
80 & 0.7 & & & & \\
81 & + & 1.3 & & & \\
82 & & & 0.9 & 0.9 & 1.3 \\
91 & & & & & + \\
93 & & & & & + \\
95 & + & & 0.5 & + & + \\
109 & & & & & \\
\hline
\end{tabular}


requires at least the cleavage of two bonds, surviving $[\mathrm{M}-\mathrm{H}]^{+}$ions are not detected. This is also true for the CR mass spectra of the enolates from the alkylated cyclohexanones 14-19. Instead, the dominant fragments in all cases are the ions of $m / z \quad 27\left(\left[\mathrm{C}_{2} \mathrm{H}_{3}\right]^{+}\right), 39$ $\left(\left[\mathrm{C}_{3} \mathrm{H}_{3}\right]^{+}\right), 41 \quad\left(\left[\mathrm{C}_{3} \mathrm{H}_{5}\right]^{+}\right)$and $55\left(\left[\mathrm{C}_{4} \mathrm{H}_{7}\right]^{+}\right.$or $\left[\mathrm{C}_{3} \mathrm{H}_{3} \mathrm{O}\right]^{+}$), and specific fragmentations corresponding to the loss of $\mathrm{CO}$ or the alkyl substituents are not abundant or even missing. Therefore, the peak pattern in the CR spectra of the enolate ions of the three isomeric methylcyclohexanones (Table 4) and of the three isomeric ethylcyclohexanones (Table 5) are similar, and the small $S I$ values (Tables 6 and 7) show that it is not possible to distinguish between isomeric alkylcyclohexanones by the CR mass spectra of their enolate ions.

Table 5. CR mass spectra of the enolate ions of isomeric ethylcyclohexanones $17-19 m / z 125$ )

\begin{tabular}{rcrc}
$m / z$ & 17 & 18 & 19 \\
14 & + & & 0.9 \\
15 & 0.9 & 3.0 & 0.8 \\
27 & 15.8 & 13.6 & 16.7 \\
29 & 6.4 & 7.8 & 6.3 \\
39 & 17.7 & 14.1 & 16.2 \\
41 & 14.5 & 15.6 & 15.4 \\
51 & 3.6 & 4.4 & 3.8 \\
53 & 6.3 & 6.7 & 5.9 \\
55 & 17.0 & 13.9 & 18.0 \\
63 & 0.8 & & 1.0 \\
65 & 2.4 & 3.3 & 2.6 \\
67 & 6.0 & 6.7 & 5.3 \\
77 & 1.7 & 2.3 & 1.3 \\
79 & 2.3 & 5.6 & 1.9 \\
81 & 1.7 & 3.8 & 2.1 \\
83 & 0.5 & & 0.6 \\
91 & + & & + \\
95 & 1.0 & & 0.7 \\
107 & + & & + \\
109 & + & & + \\
\hline
\end{tabular}

Table 6. SI values of the CR mass spectra of $[M-H]^{-}$ions of 13-16

\begin{tabular}{ccccc} 
& 13 & 14 & 15 & 16 \\
13 & - & 688 & 989 & 537 \\
14 & & - & 25 & 140 \\
15 & & - & 145 \\
16 & & & & - \\
\hline
\end{tabular}

Table 7. SI values of the CR mass spectra of $[\mathrm{M}-\mathrm{H}]^{-}$ions of 17-19

\begin{tabular}{cccc} 
& 17 & 18 & 19 \\
17 & - & 101 & 48 \\
18 & & - & 81 \\
19 & & & - \\
\hline
\end{tabular}

CR spectra of the $\left[\mathrm{C}_{10} \mathrm{H}_{15} \mathrm{O}\right]^{-}$ions from monoterpene ketones 20-23<smiles>CC12CCC(CC1=O)C2(C)C</smiles>

20<smiles>CC(C)=C1CCC(C)C(=O)C1</smiles><smiles>CC12CCC(CC1=O)C2(C)C</smiles>

21<smiles>CC1C(=O)CC2(C(C)C)CC1C2</smiles>

The investigation of the CR spectra of $[\mathrm{M}-\mathrm{H}]^{-}$ions from ketones was extended to the four terpene ketones, camphor (20), fenchone (21), pulegone (22) and thujone (23). The CR spectra of their $[\mathrm{M}-\mathbf{H}]^{-}$ions are listed in Table 8 . Note that 21 does not contain $\alpha$-hydrogen atoms adjacent to the carbonyl group and should not produce enolate ions by reaction with $\mathrm{OH}^{-}$. Nonetheless, $[\mathrm{M}-\mathrm{H}]^{-}$ions are formed as easily as from the other ketones in the $\mathrm{NCI}\left(\mathrm{OH}^{-}\right)$mass spectra. These

Table 8. CR mass spectra of enolate ions of the monoterpene ketones 20-23 (m/z 151)

\begin{tabular}{rrrrr}
$m / 2$ & \multicolumn{1}{c}{19} & 20 & \multicolumn{1}{l}{22} & \multicolumn{1}{c}{$\mathbf{2 3}$} \\
15 & 0.6 & + & 0.5 & 0.5 \\
27 & 7.6 & 6.9 & 6.5 & 7.9 \\
29 & 2.4 & 2.3 & 2.1 & 2.7 \\
39 & 14.8 & 13.0 & 15.8 & 13.0 \\
41 & 12.4 & 12.4 & 14.6 & 11.2 \\
43 & 2.4 & 3.8 & 2.7 & 4.6 \\
51 & 6.3 & 5.4 & 6.8 & 6.4 \\
53 & 6.4 & 5.9 & 7.1 & 7.1 \\
55 & 4.1 & 2.9 & 3.4 & 4.7 \\
63 & 2.0 & 1.6 & 1.9 & 2.1 \\
65 & 4.1 & 4.0 & 5.5 & 4.5 \\
67 & 5.5 & 3.4 & 7.3 & 3.9 \\
69 & 1.9 & 1.8 & 2.1 & 1.4 \\
77 & 6.5 & 7.9 & 4.9 & 6.9 \\
79 & 5.7 & 9.7 & 5.4 & 6.6 \\
81 & 2.2 & & 2.0 & 2.2 \\
83 & 1.1 & & & \\
91 & 6.3 & 7.5 & 4.1 & 5.5 \\
93 & 2.2 & 3.9 & 2.1 & 2.7 \\
95 & 1.1 & 1.1 & 1.0 & 1.2 \\
105 & 1.3 & 1.9 & 1.0 & 1.5 \\
107 & 1.7 & 2.7 & 1.5 & 2.2 \\
121 & 0.6 & 0.6 & 0.5 & 0.5 \\
123 & + & + & + & + \\
135 & + & + & 0.5 & + \\
149 & & & + & \\
\hline
\end{tabular}


Table 9. SI values of the $\mathrm{CR}$ mass spectra of $[\mathrm{M}-\mathrm{H}]^{-}$ions of 20-23

\begin{tabular}{ccccc} 
& 20 & 21 & 22 & 23 \\
20 & - & 205 & 99 & 93 \\
21 & & - & 69 & 39 \\
22 & & - & 54 \\
23 & & & & - \\
\hline
\end{tabular}

ions must be due to homoenolate ions of the bicyclic ketone. $^{20}$

As in the CR spectra of the alkyl cyclohexanones, the peaks of the ions of $\mathrm{m} / \mathrm{z} 39$ and 41 predominate in the CR spectra of 20-23 and the losses of $\mathrm{CO}$ and of alkyl substituents are not abundant. It is interesting that the charge-reversed $[\mathrm{M}-\mathrm{H}]^{+}$ions $(\mathrm{m} / z$ 151) can be detected in the CR mass spectra of 20-23. This probably reflects the polycyclic structure of these terpene ketones, which necessitates multiple bond cleavages for degradation. However, the $C R$ mass spectra of the $[\mathrm{M}-\mathrm{H}]^{-}$ions from 20-23 cannot be used for the identification of these terpene ketones, as shown by the small $S I$ values (Table 9). Since the structures of the neutral precursors are clearly different, this is an unexpected result which hints at isomerization processes at some stage of the CR procedure. Either the rigid structure of the monoterpene ketones promotes the isomerization of the $[\mathbf{M}-\mathbf{H}]^{-}$ion, or isomerization takes place in the highly excited $[\mathrm{M}-\mathrm{H}]^{+}$ions. The observation that the $C R$ mass spectra are always governed by the peaks of small and structurally unspecific hydrocarbon ions, indicating fragmentations by multi-step processes, makes the latter explanation more probable.

\section{CONCLUSION}

The results of this study of the CR technique as an analytical tool for the structure elucidation and identification of organic compounds show a divided picture. The technique applied to aliphatic ketones yields intense CR mass spectra, demonstrating that the charge-reversed enolate ions accommodate sufficient excess energy for extensive fragmentations. In the case of open-chain enolate ions the characteristic fragmentations subsequent to charge reversal are $\alpha$-cleavages giving rise to acylium ions and ketene radical cations. These ions and their daughter ions formed by loss of $\mathrm{CO}$ can be used to establish the structure of the parent ketone in a similar fashion as in the normal positive electron impact (EI) mass spectra of the ketones. However, most of the ion current in the CR mass spectra of the enolate ions is due to small hydrocarbon ions which are of limited use for an interpretation aimed at a structure determination. Nevertheless, in the case of the open-chain ketones studied it is possible to distinguish isomers by their enolate CR mass spectra using the SI values and a library of reference spectra. In contrast, the CR method failed completely in the analysis of most of the cyclic ketones studied. The CR mass spectra of the corre- sponding cyclic enolates are devoid of characteristic peaks due to cleavages of substituents at the ring and are dominated by unspecific hydrocarbon ions. Apparently the large amount of excess energy imparted by the charge reversal to the $[\mathrm{M}-\mathrm{H}]^{+}$effects a degradation to small fragment ions. Thus, although a combination of NCI mass spectrometry for a relative molecular mass determination and of CR mass spectrometry is of advantage for the analysis of certain compounds, it is by no means an analytical technique for general application.

\section{EXPERIMENTAL}

All charge-reversal experiments were performed with a VG ZAB-2F mass spectrometer of reversed geometry using a combined EI/CI source. The following conditions were used for ion generation by $\mathrm{NCI}$ : electron energy, $100 \mathrm{eV}$; emission current, $0.5 \mathrm{~mA}$; acceleration voltage, $6 \mathrm{kV}$; and ion source temperature, $\sim 180^{\circ} \mathrm{C}$ The plasma ion $\mathrm{OH}^{-}$was generated from a $1: 1$ mixture of methane and dinitrogen oxide. The pressure at the ion-gauge head below the ion source housing was $1 \times 10^{-5}-5 \times 10^{-5}$ mbar and was optimized for sample ion intensity. Liquid samples were introduced via a septum inlet system at $\sim 180^{\circ} \mathrm{C}$ and solid samples via a direct inlet system. Under these conditions the $[\mathrm{M}-\mathrm{H}]^{-}$ions of the ketones predominated by far in the NCI mass spectra.

For a charge reversal the negative ions were transmitted through the magnetic sector into the second fieldfree region and underwent collisions with helium in the collision cell. Helium was introduced at such a rate as to reduce the main beam intensity to $\sim 50 \%$. The positive fragment ions produced were analysed by scanning the voltage applied to the electrostatic analyser with the polarity of the voltage appropriate for positive-ion transmission ( $+E$ spectra).

The structures of the compounds used were checked by the $70 \mathrm{eV}$ EI mass spectra and ${ }^{1} \mathrm{H}$ NMR spectra, and the purity of the synthesized compounds was established by gas chromatography (OV-1 column, carrier gas helium).

The following substrates were commercially available and used without further purification: heptan-4-one (1), heptan-2-one (3), heptanal (4), 5-methylhexan-2-one (5), 3-ethylpentan-2-one (8), 4,4-dimethylpentan-2-one (9), cyclohexanone (12), cycloheptanone (13), 3-methylcyclohexanone (15), camphor (20), fenchone (21), thujone (22) and pulegone (23).

Heptan-3-one (2) was prepared by the reaction of butylmagnesium bromide with propionic anhydride in tetrahydrofuran (THF); ${ }^{21}$ yield $90 \%$, b.p. $60^{\circ} \mathrm{C} / 25$ Torr $(1$ Torr $=133.3 \mathrm{~Pa})$.

4-Methylhexan-2-one (6) was obtained by the reaction of the Grignard compound of 1-bromo-2-methylbutane with acetyl chloride and $\mathrm{Fe}(\mathrm{acac})_{3}$ in $\mathrm{THF} ;^{22}$ yield $30 \%$, b.p. $82^{\circ} \mathrm{C} / 140$ Torr.

3-Methylhexan-2-one (7) was synthesized by the reaction of methylmagnesium iodide with 2methylpentanal followed by oxidation of the resulting alcohol in diethyl ether with sodium dichromate- 
sulphuric acid using standard methods of organic chemistry; overall yield $17 \%$, b.p. $62^{\circ} \mathrm{C} / 45$ Torr.

3,3-Dimethylpentan-2-one (10) was synthesized from methylmagnesium iodide, 2,2-dimethylbutyl chloride and $\mathrm{Fe}(\mathrm{acac})_{3}$ in THF as described previously; ${ }^{20}$ yield $36 \%$, b.p. $130^{\circ} \mathrm{C} / 760$ Torr.

3,4-Dimethylpentan-2-one (11) was prepared via alkylation of ethyl acetoacetate with 2-bromopropane in the presence of sodium ethanolate followed by methylation with methyl iodide and sodium hydride in dimethylformamide by standard procedures. This twofold substituted acetoacetate ester was hydrolysed and decarboxylated by heating with $2 \mathrm{M}$ hydrochloric acid; yield $15 \%$, b.p. $52^{\circ} \mathrm{C} / 40$ Torr.

4-Methylcyclohexanone (16) was obtained from 4methylcyclohexanol by oxidation with sodium dichromate-sulphuric acid in diethyl ether; yield $42 \%$, b.p. $55^{\circ} \mathrm{C} / 16$ Torr.

2-Ethylcyclohexanone (17) was obtained by alkylation of $N$-cyclohexylidenecyclohexylamine. ${ }^{23}$ The imine was synthesized by heating a mixture of cyclohexanone, cyclohexylamine and benzene using a water separator; yield $53 \%$, b.p. $84^{\circ} \mathrm{C} / 0.4$ Torr. The imine was deprotonated with ethylmagnesium bromide in THF. Subsequently bromoethane was added and the reaction product was hydrolysed with $1.5 \mathrm{M}$ hydrochloric acid; yield $51 \%$, b.p. $67^{\circ} \mathrm{C} / 20$ Torr.

3-Ethylcyclohexanone (18) was prepared by a 1,4addition of ehtylmagnesium bromide to cyclohex-2-en1 -one in the presence of copper(I) iodide as a catalyst in THF $;{ }^{24}$ yield $45 \%$, b.p. $76^{\circ} \mathrm{C} / 25$ Torr.

4-Ethylcyclohexanone (19) was prepared from 4ethylcyclohexanol by oxidation with sodium dichromate (yield $81 \%$, b.p. $77^{\circ} \mathrm{C} / 20$ Torr). The alcohol was obtained by hydrogenation of 4-ethylphenol under pressure in an autoclave with Raney nickel as a catalyst ${ }^{25}$ (yield 82\%).

\section{Acknowledgements}

The financial support of this work by the Deutsche Forschungsgemeinschaft and by the Fonds der Chemischen Industrie is gratefully acknowledged.

\section{REFERENCES}

1. K. R. Jennings in Mass Spectrometry, Specialist Periodical Report, ed. by R. A. W. Johnstone, Vol. 4, p. 203. Chemical Society, London (1977).

2. H. Budzikiewicz, Mass Spectrom. Rev. 5, 345 (1986).

3. J. H. Bowie, Mass Spectrom. Rev. 3, 161 (1984).

4. F. W. McLafferty (Ed.), Tandem Mass Spectrometry. Wiley, New York (1983).

5. (a) J. H. Bowie and T. Blumenthal, J. Am. Chem. Soc. 97, 2959 (1975): (b) I. Howe, J. H. Bowie, J. E. Szulejko and J. H. Beynon, Int. J. Mass Spectrom. Ion Phys. 34, 99 (1980).

6. (a) J. P. Kiplinger, A. T. Maynard and M. M. Bursey, Org. Mass Spectrom. 22, 534 (1987); (b) T. A. Lehman, M. M. Bursey and J. R. Hass, Org. Mass Spectrom. 18, 373 (1983); (c) M. M. Bursey, D. J. Harvan, C. E. Parker and J. R. Hass, J. Am. Chem. Soc. 105, 6801 (1983); (d) M. M. Bursey, J. R. Hass, D. J. Harvan and C. E. Parker, J. Am. Chem. Soc. 101, 5485 (1979); (e) P. C. Burgers and J. L. Holmes, Org. Mass Spectrom. 19, 452 (1984).

7. J. H. Bowie, Acc. Chem. Res. 13, 76 (1980).

8. (a) D. F. Hunt, J. Shabanowitz and A. B. Giordani, Anal. Chem. 82, 386 (1980); (b) D. F. Hunt, A. B. Giordani, J. Shabanowitz and G. Rhodes, J. Org. Chem. 47, 738 (1982).

9. S. Chowdhury and A. G. Harrison, J. Am. Chem. Soc. 110 7345 (1988).

10. A. Donnelly, S. Chowdhury and A. G. Harrison, Org. Mass Spectrom. 24, 89 (1989).

11. M. B. Stringer, D. J. Underwood, J. H. Bowie, J. L. Holmes, A. A. Mommers and J. E. Szulejko, Can. J. Chem. 63, 764 (1986).
12. M. B. Stringer, J. H. Bowie and J. L. Holmes, J. Am. Chem. Soc. 108, 3888 (1986).

13. J. H. Bowie, M. B. Stringer and G. J. Currie, J. Chem. Soc. Perkin Trans. 21821 (1986).

14. R. N. Hayes, J. C. Sheldon and J. H. Bowie, Int. J. Mass Spectrom. Ion Processes 71, 233 (1986).

15. G. J. Currie, M. B. Stringer, J. H. Bowie and J. L. Holmes, Aust. J. Chem. 40, 1365 (1987).

16. M. J. Raftery and J. H. Bowie, Int. J. Mass Spectrom. Ion Processes 79, 267 (1987).

17. Ni. J. Raftery and J. H. Bowie, Aust. J. Chem. 40, 711 (1987).

18. J. O. Lay, Jr, M. L. Gross, J. J. Zwinselman and N. M. M. Nibbering, Org. Mass Spectrom. 18, 16 (1983).

19. T. Sürig and H.-F. Grützmacher, Org. Mass Spectrom. 24, 851 (1989).

20. A. L. Johnson, J. B. Stothers and C. T. Tan, Can. J. Chem. 53, $212(1975)$, and references cited therein.

21. M. S. Newman and A.S. Smith, J. Org. Chem. 13, 592 (1948).

22. V. Fiandanese. G. Marchese, V. Martina and L. Ronzini, Tetrahedron Lett. 25, 4805 (1984).

23. A. J. Meyers, D. R. Williams and M. Druclinger, J. Am. Chem. Soc, 98,3032 (1976).

24. H. O. House, W. L. Respess and G. M. Whitesides, J. Org. Chem. 31, 3128 (1966).

25. H. J. Rimek, in Houben-Weyl, ed. by H. Kropf and E. Müller, 4th ed., Vol. 4/1 c, p. 177. Thieme, Stuttgart (1980). 